\title{
La apropiación de niños en España y Argentina. Dos políticas de la memoria
}

A principios de 2002 se emitió en $T_{3}$ el documental Els nens perduts del franquisme, basado en las investigaciones del historiador Ricard Vinyes sobre las presas políticas y sus hijos en las cárceles franquistas. Hasta ese día las pocas noticias que se tenían de las apropiaciones venían del otro lado del Atlántico. Las dictaduras latinoamericanas de los años setenta habían marcado el mundo occidental con el fantasma de los desaparecidos y con el robo de sus hijos para "salvarlos" y reeducarlos. Este artículo tiene como objetivo un acercamiento a las consecuencias de los robos en la construcción de la memoria individual y colectiva de España y de Argentina. Para hacerlo se realiza un breve recorrido por las producciones culturales más importantes de ambos países hasta el año 2014 inclusive. Tanto en el contexto histórico como en las narrativas se indagará no solo en los puntos en común sino también en las divergencias, trayendo a colación los estudios de Pilar Calveiro sobre el totalitarismo y los estudios de Ricard Vinyes, Raquel Macciuci, Esteso Poves, Ludmila Da Silva y Gabriel Gatti sobre los contextos español y argentino.

"He buscado desdibujar los límites entre
documento y ficción; he buscado que el texto
fuera, ante todo, un hecho literario, con todo
lo que esto implica de sinuoso y de ambiguo.
No sé con qué fragmentos de la realidad
cotejará cada lector cuáles fragmentos de
este libro. Sé que, para mí, su escritura fue
un modo de atarme a la memoria, por
incómoda o intolerable que esta memoria
fuera. Un intento, tal vez, de reconstruirme".
Liliana Heker. El fin de la historia

Si pensamos en los dramas genealógicos del Siglo de Oro o en la Gran Bretaña del siglo XIX con comedias como La importancia de llamarse Ernesto (1895), de Oscar Wilde, es fácil advertir el conjunto de valores que se le atribuye al linaje. ${ }^{1}$ Esta tradición genealógica y el peso que se le asigna en la construcción de los grupos culturales no pasa desapercibido para los 
Estados totalitarios del siglo XX, que centrarán gran parte de su política en la devastación de la identidad, en el quiebre de todo aquello que constituye al otro, al diferente (por raza, por religión, por ideología) en un sujeto social.

El totalitarismo se constituyó como una organización binaria de la sociedad "en un Uno Estatal y Otro prescindible y peligroso que debía y merecía ser destruido" (Calveiro 362; énfasis en el original). En esta secuencia hubo un patrón totalitario: los Estados tuvieron pretensiones de dominio mundial, intervinieron tanto en la vida pública como en la privada de los ciudadanos, impusieron el exterminio de grupos humanos por su identidad racial, religiosa o política; instituyeron campos de concentración y recurrieron al terror como instrumento de control social. Los Estados implantaron una política de destrucción hacia dentro y hacia afuera de la sociedad totalitaria (Calveiro). En estos procesos, el desarme genealógico y el ataque a la identidad se constituyeron como un modo más de dominio y un instrumento para asegurarse la extensión en el tiempo de la ideología totalitaria. Por eso, apropiarse de los niños de los vencidos y alterar su filiación fue parte del proceso de borramiento del otro. El equipo psicológico de Abuelas de Plaza de Mayo subraya que cuando un bebé nace, la primera identificación subjetiva es con los padres, ellos inscribirán en él una huella simbólica, el "trazo identificatorio que le permitirá ser": un nombre, un apellido, una historia familiar, un grupo social. Por eso, Alicia Lo Giúdice, responsable del Equipo Terapéutico de Abuelas de Plaza de Mayo, insiste en la violencia sobre la identidad y sobre la genealogía familiar que supone la negación del nombre:

Uno se nombra como ha sido nombrado y al nombrarse nombra la relación de uno con sus progenitores, aquél que lo incluyó en el orden de las generaciones ... En cada inscripción se marca el lugar que el sujeto ocupa en el orden de las generaciones que es único y que abre el camino a nuevos eslabones en el sistema de parentesco. ("Área")

Es así como la apropiación de niños, en todas sus formas y épocas, ha funcionado como una herramienta de dominación sobre los derrotados y como un dispositivo de perpetuación del poder de quienes detentan la hegemonía, ya sea política, religiosa, ideológica o territorial.

Si bien los casos latinoamericanos de apropiaciones de menores actuaron como referentes inmediatos y como marco de actuación para llegar a conclusiones similares respecto a la dictadura española, no fue hasta el año 2002 que salieron a la luz las primeras pesquisas sobre el robo de niños en el franquismo. Hay que tener en cuenta que el caso más 
notorio y que más ha trascendido, el de Argentina, no es el único antecedente. A lo largo de la historia de las guerras, la conquista ha estado casi siempre ligada al rapto de mujeres y niños, que solían ser utilizados como mano de obra y esclavos; claro que en muchos de estos casos hablamos de naciones extranjeras que invaden un territorio y no de un Estado que se levanta contra aquellos que debería proteger. De una u otra manera, los raptados, los saqueados, se transforman en un botín de guerra y pasan a engrosar las filas del ejército vencedor. En el desarrollo del presente trabajo hablaré de apropiación para referirme a la sustracción ilegal de menores por parte de la última dictadura militar argentina. Este vocablo, aunque con algunas controversias por parte de los afectados, ya ha sido cristalizado en el mundo de los Derechos Humanos y está asociado directamente con la lucha de Abuelas de Plaza de Mayo (en adelante APM). ${ }^{2}$ En el caso español, sin embargo, no hay hasta el momento un consenso sobre cómo denominar el robo de niños por parte del Estado. Podemos encontrar que se mencionan como "niños robados", "niños perdidos", "niños desaparecidos", a veces, muy pocas, "apropiación de niños". La falta de concreción para nombrar el acto delictivo y sus consecuencias se debe, a mi entender, a la novedad y a la envergadura del tema. De hecho, es en este momento cuando estamos asistiendo al proceso de conformación del robo de menores dentro de la memoria colectiva española, ya asumido como otro de los crímenes del franquismo, sin embargo, el conocimiento de los sucesos es, mayormente, exclusivo de las víctimas y de quienes abordan la memoria republicana.

Teniendo en cuenta esta dificultad, propongo la utilización del término expropiación para el caso español, porque considero que engloba una deliberación estatal avalada por leyes del gobierno totalitario, así, tanto la expropiación de bienes materiales como la de niños fue una práctica sistemática a lo largo de más de treinta años. ${ }^{3}$ Ligada a esta diferenciación, y siguiendo a María Esteso Poves, distingo dos etapas en los casos españoles: una desde la finalización de la guerra hasta la década de los 6o, producto de la represión franquista; la otra entre los 60 y los 9o, donde si bien el móvil más evidente fue el económico, siguió en su base la intención política de segregación desarrollada por el psiquiatra Juan Antonio VallejoNágera. Súmese a esto que muchos de los funcionarios vinculados a los robos en democracia también fueron los responsables directos durante la dictadura. No obstante, no deben confundirse las etapas, ya que los mecanismos fueron diferentes y la intervención estatal de los primeros años, en los últimos momentos del franquismo fue delegada a profesionales corruptos que se mantuvieron en sus funciones durante la transición y la primera década de democracia. ${ }^{4}$ 
UN ANÁliSIS TRANSATLÁNTICO DE LA APROPIACIÓN/EXPROPIACIÓN La propuesta de un enfoque transatlántico para el presente trabajo se asienta en tres basas. La primera de ellas es que Argentina fue el primer país en dar nombre a la acción delictiva, en denunciar, perseguir y llevar ante los tribunales a muchos de los responsables. La segunda tiene que ver con las investigaciones en los diferentes campos ligados a la restitución (Derechos Humanos, psicología, leyes, educación, etc.), donde los especialistas del Cono Sur han sido pioneros y aun son referentes para la construcción de un marco de actuación legal en España. Prueba de esto es que las asociaciones españolas que representan a afectados por los robos de niños, en dictadura y en democracia, y a descendientes de los represaliados por el franquismo, han recurrido a tribunales argentinos para llevar adelante sus causas. Las diferentes unidades que trabajan en la localización y exhumación de las fosas comunes y en la restitución de los niños en Argentina han ayudado a los equipos españoles en el avance sobre los casos ibéricos. ${ }^{5}$ Asimismo, desde hace ya más de una década, el léxico utilizado en las investigaciones españolas para designar a las víctimas del franquismo también se ha abastecido de los estudios argentinos. Ejemplo de ello son las acepciones "desaparecidos" y “apropiación". 6

El tercer punto que justifica el enfoque transatlántico surge ante la recurrente comparación de ambos casos tanto por parte de historiadores, como es el caso de Vinyes; de testigos, como es el caso de Tomasa Cuevas; o de afectados. ${ }^{7}$ Un acercamiento al tema español sin confrontarlo con el argentino supondría un importante déficit para entender la motivación en las formas de representación de la problemática.

No obstante, debo destacar que, a la hora de plantear una relación dialógica entre los casos de ambos países, han influido sobre el modo en que debería hacerlo algunos estudios puntuales, entre ellos destaco, para el ámbito específicamente español, la noción de "internacionalización de la memoria" de Raquel Macciuci, quien exhorta a preservar los detalles que constituyen la experiencia intransferible del caso ibérico. Su reclamo es que quien tome para sí el legado de la memoria utilice, cual antropólogo, los utensilios necesarios para no "dañar los preciosos restos que le han encomendado recobrar" (49). Con los acontecimientos traumáticos del siglo XX es factible ver en las experiencias del Holocausto, de las dictaduras latinoamericanas o del colaboracionismo de Vichy, antecedentes para los estudios de la memoria propia. Sin embargo, la particularidad de la Guerra Civil española requiere un tratamiento diferente al de otras situaciones. De este modo, aunque en un primer momento la incorporación de la historia española a la de las aberraciones del resto de Europa y Latinoamérica 
sirvió como pivote para adentrarse en el pasado traumático y en las formas de evocación y, aunque la dictadura franquista también arrojó luz para comprender otros gobiernos totalitarios, la tesis sobre la "internacionalización de la memoria" (Macciuci) advierte que la memoria no se vale solo del impulso moral sino también de las singularidades. Las particularidades de cada caso son insustituibles, no se pueden homologar los horrores de los diversos regímenes porque se borraría lo intransferible de cada una de las experiencias.

LA REPRESENTACIÓN DE LA EXPROPIACIÓN DE MENORES EN ESPAÑA En abril de 2015 se trasmitió en la televisión catalana Els internats de la por, el tercer documental de Montse Armengou y Ricard Belis, que tiene como núcleo temático la violencia del franquismo en la infancia. La trilogía tuvo su inicio con Els nens perduts del franquisme (2002), y Torneu-me el fill! (2012). En los tres casos hubo una intención precisa detrás de los contenidos elaborados. No solamente se trataba de informar de los acontecimientos, sino que se buscó producir un pasado. No fueron rememoraciones independientes, con víctimas aisladas, sino que hubo en el conjunto una producción en el marco de un proyecto mayor, cuya intención fue "una conexión de sentidos" que permitieran reconocer y vincular los procesos pretéritos con las políticas actuales. ${ }^{8}$ En esta articulación de pasado, presente y futuro, se constituyó una "práctica resistente" (Calveiro 379) y se reclamó una revisión histórica de los sucesos y un compromiso político e institucional con las víctimas directas del robo de niños durante el franquismo. El documental se propuso, de este modo, como una máquina de memoria que no reproducía solamente sucesos del pasado sino que disparaba sentidos desde el presente.

Sin embargo Els nens perduts del franquisme no solo se trató de un reportaje televisivo sino que fue la fase final de una investigación histórica anterior. En la génesis de la emisión hubo un largo trabajo de indagación y análisis historiográfico. El proyecto comenzó como un estudio sobre la cárcel de mujeres en el franquismo, en el transcurso del mismo Ricard Vinyes llegó a la evidencia de que también había “otros presos, unos presos ignorados, de los que nadie había hablado: los niños, las víctimas inocentes. Niños y niñas que habían cometido el delito de ser hijos de rojos" (Armengou, Nens 16). Pocos meses después de la emisión del documental se publicó el estudio original con el nombre de Irredentas. Las presas políticas y sus hijos en las cárceles de Franco (Vinyes), en el mismo, los niños ocuparon una parte importante de la investigación, pero no fueron los únicos protagonistas, la principal atención fue para las presas políticas. ${ }^{9}$ De este modo, a partir de la exposición pública de la tragedia en 
las cárceles, orfanatos y centros del Auxilio Social, se vuelve la mirada hacia aquellos productos que habían surgido durante la transición y que habían sido descapitalizados en la construcción del nuevo Estado por pertenecer a la memoria republicana.

Así, entre las producciones autobiográficas más importantes sobre el destino de los huérfanos de la guerra se encuentra el cómic de Carlos Giménez, Paracuellos. ${ }^{10}$ Publicado inicialmente durante la Transición y continuado en diferentes fases, contiene unas 600 páginas donde pululan y rebalsan huérfanos del Auxilio Social. Esta historieta ilustra la vida en varios centros donde pasó su infancia Carlos Giménez. En sus viñetas se denuncia la humillación, las torturas, el hambre, la re-educación militar y religiosa. En sus páginas queda al desnudo el concepto de herencia del franquismo, la segregación de los niños para que no crecieran en ambientes republicanos, y la reeducación para que se transformaran en defensores de la España Una, Grande, y Libre del Caudillo. Todas las viñetas están en blanco y negro y recuerdan la carencia de los hogares (ausencia de padres, de afecto, de comida y de posibilidades). Los prologuistas de Paracuellos coinciden en imágenes que evocan la devastación y la imposibilidad de olvidar: "el infierno de la memoria" (Jesús Cuadrado), "la huella infinita” (José María Beá).

También destaco la obra de Michel del Castillo, Tanguy. Historia de un niño de hoy (1957), una novela de carácter autobiográfico donde el autor relata la soledad de un niño que tiene que sobrevivir a las duras experiencias de un contexto en guerra. ${ }^{11}$ Huye desde Valencia a Francia con su madre. Allí, luego de rocambolescos sucesos que incluyen 18 meses en un campo de concentración al sur del país, su madre lo abandona para cruzar la frontera y volver a España. La promesa de un reencuentro en Madrid nunca llega a cumplirse porque el niño es detenido, recluido en el Velódromo de Invierno y más tarde enviado a Mauthausen.

Antonio Muñoz Molina, que escribe el prólogo a la edición española de Tanguy (1999), recoge la experiencia trágica de Michel del Castillo en Sefarad: "Yo he conversado con alguien que a los seis años se moría de miedo abrazado a su madre en un sótano de Madrid mientras sonaban las sirenas de alarma, los motores de los aviones y los estampidos de las bombas, y que a los diez años estaba internado en un barracón de Mauthausen" (169). Una vez acabada la Segunda Guerra Mundial Tanguy/Michel es repatriado e internado en el centro Toribio Durán de Barcelona, donde también pasó algún tiempo Carlos Giménez. La estancia en este sitio representa una experiencia dramática por la crueldad del sistema y la doble moral de quienes lo representaban: 
Si por casualidad un extraño venía a visitar el Centro, había que fingir entusiasmo, reír, correr con rapidez, dejarle "boquiabierto". Tanguy detestaba aquella duplicidad. Miraba cómo sus compañeros, extenuados por la fatiga y el hambre, se esforzaban en gritar y reír ... Tanguy aprendió en el Centro el difícil arte de odiar. (Castillo 190)

Esto en cuanto a los antecedentes testimoniales de quienes vivieron en los asilos del Auxilio Social. La nueva generación de narradores españoles también ha recuperado el lugar de la infancia y ha denunciado en sus tramas la sustracción de menores por parte del Estado franquista. Primero quisiera subrayar la significativa diferencia en la reconstrucción de las expropiaciones desde el ámbito teatral y desde el espacio de la novela. Mientras que las novelas sobre los niños apropiados - Mala gente que camina (2006) de Benjamín Prado y Si a los tres años no he vuelto (2011) de Ana Cañil - se valen del discurso historiográfico a tal punto que hacen de él el epicentro de la narración, las representaciones teatrales han optado por la creación de escenas más oníricas, espectrales y esencialmente simbólicas. El ámbito teatral ha traído, literalmente, al presente del espectador a los desaparecidos, a los perdidos en las fosas y en los orfanatos. Con este recurso, más allá de la intención estética, hay un propósito de intervención social y una construcción activa de la memoria de la que se hace partícipe al público. Se trata de un teatro heredero de la revolución brechtiana, que se concibe como "un arte de la explicación, y no ya solamente un arte de la expresión", y que por lo tanto "deja de ser mágico para convertirse en crítico" (Barthes 62). Los actores que se mueven en escena colaboran en la toma de conciencia, "denunciando su papel, no encarnándolo ... el espectador no debe nunca identificarse completamente con el héroe, de modo que pueda seguir siendo libre de juzgar las causas, y más tarde los remedios, de su sufrimiento" (Barthes 6162).

Ambos géneros responden a la necesidad de reparación y a una reconstrucción de los episodios traumáticos, pero el impacto visual del que puede valerse el teatro ha permitido que obras como Si un día me olvidaras (Hernández Garrido, 2000), Presas (Fernández y Del Moral, 2007), Los niños perdidos (Ripoll, 2005) y NN12 (Morales, 2008) puedan verse reforzadas por personajes con los que la narrativa de la memoria española apenas se ha atrevido: fantasmas, espíritus y montajes sangrientos. Las puestas en escena espectrales trasmiten aquello que la novela ejemplifica a través de la insistencia histórica, para interpelar al espectador y para que el recuerdo de los niños perdidos encuentre su sitio en la memoria colectiva. En cambio, en novelas como Mala gente que camina y Si a los tres 
años no he vuelto tiende a confundirse, y en algunos casos a difuminarse, la tarea del novelista con la del historiador. Estas narrativas parecen ahogar sus posibilidades en una continua repetición de documentos. Así, la saturación informativa contribuye a la pérdida de efecto crítico y, por lo tanto, no hay conflicto ni desafío para el lector. No entraré en un análisis pormenorizado de las obras, pero un simple repaso por las resoluciones en cuanto a la restitución o no de la identidad de los personajes nos permite un acercamiento. En Mala gente que camina, Lisvano, el sobrino de Dolores Serma que creció bajo un nombre ficticio, es obligado por el narrador a enfrentarse a la verdad, pero la rechaza: "Resulta doloroso que, una vez que Carlos Lisvano, o Bates, pudo saber la verdad, no la haya considerado honorable, sino una tara, y prefiera mantenerla oculta. Seguramente, él también sea, en toda su extensión, un arquetipo, un mal síntoma" (Prado 445). Si Lisvano actúa de ese modo es por la falta de trasmisión de la historia, su familia (su tía) le impuso la misma censura que imponen los expropiadores: cambio de nombre, negación de la ideología republicana de sus padres. De este modo, Dolores Serma funciona como una alegoría de la transición, su pacto de desmemoria (el personaje acaba con Alzheimer) termina dejando secuelas irreparables en la próxima generación.

En Si a los tres años no he vuelto Luisito, el niño que nace en la cárcel y es robado por María Topete, es restituido pero a partir de un inverosímil narrativo que deja en evidencia la imposibilidad en el plano de la realidad, ya que los menores que perdieron su identidad en el régimen de Franco (salvo excepciones) lo hicieron para siempre. ${ }^{12}$ En estas narrativas se figura el conocimiento final sobre los lazos biológicos como un hecho prácticamente imposible. Las dramaturgias son menos optimistas aún, la restitución no se da ni siquiera como resolución asombrosa. En Los niños perdidos los personajes recuerdan quiénes fueron sus padres pero no pueden llegar a ellos, mueren en el orfanato a manos de una monja. Orestes en Si un día me olvidaras no sabe nada de su origen y, si hacia el final parece hallarlo por medio de Electra, eso no será más que un eco en su memoria. Tanto en Los niños perdidos como Si un día me olvidaras hablamos de fantasmas y de recuerdos que están en la memoria de uno de los personajes (Tuso y Orestes respectivamente). Son obras que evocan a quienes nunca podrán reencontrarse con su pasado. La única posibilidad que otorgan al espectador es la del mundo de ultratumba. Otras dramaturgias como $N_{12}$ sí proponen una restauración de la identidad, aunque no un reencuentro con la familia, ya que en este caso la incógnita sobre la procedencia se resuelve a través de una autopsia. Por último, destaco dos obras que llevan a las tablas los robos de menores dentro de las prisiones franquistas Presas y La sonrisa del caudillo (Buren, 2010). 
Ambas representan explícitamente la locura, la enajenación y los abusos en la cárcel de mujeres y se cierran con el robo de los bebés de las reclusas.

LA REPRESENTACIÓN DE LA APROPIACIÓN DE MENORES EN ARGENTINA

A diferencia de lo que sucede en el territorio español, el quiebre histórico que produjeron las dictaduras latinoamericanas en general y la argentina en particular, se ha convertido en parte de la vida política, social e incluso cotidiana de los argentinos. Y si bien son muchos los episodios, actores y circunstancias que podemos asociar a los sucesos, hay una imagen que representa internacionalmente la tragedia y las víctimas: los pañuelos blancos, símbolo de la lucha de Madres y Abuelas de Plaza de Mayo, que han logrado convertir su falta (los desaparecidos) en un referente global.

Desde los años de represión previos a la última dictadura comenzaron a conformarse las primeras organizaciones derecho-humanísticas; sin embargo, una vez producido el golpe, sus funciones se acotaron a acciones jurídicas. ${ }^{13}$ Así, a partir de la dictadura se organizaron nuevas asociaciones, la mayoría de ellas centradas en figuras que representaban "los lazos primordiales", los portadores de "una sustancia común", esto es las relaciones de parentesco, los lazos de sangre con las víctimas (Silva 23). Así se crea Familiares de Desaparecidos y Detenidos por Razones Políticas (1976), desde donde surgen las primeras mujeres que se acercan a la Plaza de Mayo y que luego fundan Madres de Plaza de Mayo en abril de 1977 y $A P M$ en octubre de $1977 .{ }^{14}$ Ese mismo mes de octubre se emitió una carta pública por la que se solicitaba conocer el destino de los desaparecidos. Con estos primeros avances se estableció una red de denuncias dentro y fuera del país. ${ }^{16}$

Si bien fueron muchos los intelectuales y artistas que acompañaron las acciones públicas por la verdad y la justicia de Madres y Abuelas, desde la crisis del 2001 y las medidas que dos años después tomó el gobierno de Néstor Kirchner, la producción cultural en torno a los desaparecidos y a los niños apropiados se disparó, promoviendo un amplio espectro de soportes, disciplinas y puntos de vista. ${ }^{15}$

A continuación propongo dos cuadros con las principales ficciones y documentales que se han realizado en la literatura, el cine y la televisión y que abordan la sustracción de menores. En los mismos se puede observar el incremento de la producción a partir del cambio de gobierno y la diversificación de los soportes de divulgación. Mientras en las primeras producciones se trató de películas ficcionales o documentales, a partir del 2007 se amplió el canal de difusión a la pantalla televisiva, lo que supuso un mayor alcance y un aumento en el número de espectadores. 


\begin{tabular}{|c|c|c|c|c|}
\hline Título & Dirección & País & Año & Género \\
\hline $\begin{array}{l}\text { Acá estamos. } \\
\text { Historias de nietos } \\
\text { que recuperaron su } \\
\text { identidad }\end{array}$ & $\begin{array}{l}\text { APM / TV Pública } \\
\text { Dir. Paula Romero }\end{array}$ & Argentina & 2012 & Serie TV \\
\hline Adopción & David Lipszyc & Argentina & 2010 & Ficción \\
\hline Aparecidos & Paco Cabezas & Arg. / Esp./ Suecia & 2007 & Ficción \\
\hline $\begin{array}{l}\text { Blauäugig. Ojos } \\
\text { azules }\end{array}$ & Reinhard Hauff & Arg./ Alemania & 1989 & Ficción \\
\hline Botín de guerra & David Blaustein & Arg. / Esp. & 1999 & Documental \\
\hline Cautiva & Gastón Biraben & Argentina & 2004 & Ficción \\
\hline $\begin{array}{l}\text { Chicha, esperanzay } \\
\text { dolor }\end{array}$ & $\begin{array}{l}\text { G. Kancepolsky } \\
\text { /R.Teichmann }\end{array}$ & Argentina & 2008 & Documental \\
\hline $\begin{array}{l}\text { Das Lied in Mir / El } \\
\text { día que no nací }\end{array}$ & Florian M. Cossen & Arg./ Alemania & 2010 & Ficción \\
\hline $\begin{array}{l}\text { El abismo... todavía } \\
\text { estamos }\end{array}$ & Pablo Yotich & Argentina & 2011 & Ficción \\
\hline El despertar de L. & Poli Nardi & Argentina & 2000 & Ficción \\
\hline $\begin{array}{l}\text { El recuento de los } \\
\text { daños }\end{array}$ & $\begin{array}{l}\text { Inés de Oliveira } \\
\text { Cézar }\end{array}$ & Argentina & 2010 & Ficción \\
\hline Estela & $\begin{array}{l}\text { S.Di Florio/ W. } \\
\text { Goobar }\end{array}$ & Argentina & 2008 & Documental \\
\hline Eva \& Lola & Sabrina Farji & Argentina & 2010 & Ficción \\
\hline Figli/Hijos & Marco Bechis & Italia & 2005 & Ficción \\
\hline $\begin{array}{l}\text { Generación } \\
\text { desaparecida }\end{array}$ & JanThielen & Argentina & 2003 & Documental \\
\hline Generación golpe & F. Agosta / L. Costa & Argentina & 2001 & Documental \\
\hline $\begin{array}{l}\text { Hermanos de sangre. } \\
\text { La búsqueda continua }\end{array}$ & Fabián Vittola & Argentina & 2008 & Documental \\
\hline $\begin{array}{l}\text { H.I.J.O.S, El alma en } \\
\text { dos }\end{array}$ & Céspedes / Guarini & Argentina & 2002 & Documental \\
\hline $\begin{array}{l}\text { Historias Cotidianas } \\
\text { (h) }\end{array}$ & Andrés Habegger & Argentina & 2000 & Documental \\
\hline Ilusión en movimiento & Héctor Molina & Argentina & 2001 & Ficción \\
\hline Infancia clandestina & Benjamín Ávila & Argentina & 2011 & Ficción \\
\hline La historia oficial & Luis Puenzo & Argentina & 1985 & Ficción \\
\hline La última mirada & Víctor Jorge Ruiz & Arg. / Esp. & 2010 & Ficción \\
\hline
\end{tabular}




\begin{tabular}{|c|c|c|c|c|}
\hline $\begin{array}{l}\text { Las abuelas y la } \\
\text { genética: 99,99\%. La } \\
\text { ciencia de las Abuelas }\end{array}$ & APM / TV Pública & Argentina & 2013 & Serie TV \\
\hline Los pasos perdidos & Manane Rodríguez & Arg. / Esp. & 2001 & Ficción \\
\hline $\begin{array}{l}\text { Missing children. } \\
\text { Niños desaparecidos }\end{array}$ & Estela Bravo & Argentina & 1985 & Documental \\
\hline $\begin{array}{l}\text { Montecristo, un amor, } \\
\text { una venganza }\end{array}$ & Telefé Contenidos & Argentina & 2006 & Telenovela \\
\hline $\begin{array}{l}\text { Nietos (identidady } \\
\text { memoria) }\end{array}$ & Benjamín Ávila & Argentina & 2004 & Documental \\
\hline Por esos ojos & $\begin{array}{l}\text { G. Arijón/ V. } \\
\text { Martínez }\end{array}$ & Francia / Uruguay & 1997 & Documental \\
\hline Potestad & $\begin{array}{l}\text { Luis César } \\
\text { D'Angiolillo }\end{array}$ & Argentina & 2002 & Ficción \\
\hline ¿Quién soy yo? & Estela Bravo & Arg./ EEUU/ GB & 2007 & Documental \\
\hline $\begin{array}{l}\text { Stolen babies, stolen } \\
\text { lives. Bebés robados, } \\
\text { vidas robadas }\end{array}$ & Peter Svatek & Canadá & 2008 & Documental \\
\hline $\begin{array}{l}\text { Televisión por la } \\
\text { identidad }\end{array}$ & $A P M$ & Argentina & 2007 & Unitarios TV \\
\hline $\begin{array}{l}\text { The Children of the } \\
\text { Disappeared / Los } \\
\text { hijos de los } \\
\text { desaparecidos }\end{array}$ & Susanna Handslip & Gran Bretaña & 2003 & Documental \\
\hline The Disappeared & Peter Sanders & Arg. / EEUU & 2007 & Documental \\
\hline $\begin{array}{l}\text { Verdades verdaderas. } \\
\text { La vida de Estela }\end{array}$ & Gil Lavendra & Argentina & 2011 & Ficción \\
\hline Vidas Privadas & Fito Páez & Arg. / Esp. & 2001 & Ficción \\
\hline Volver a nacer & $\begin{array}{l}\text { TV Pública } \\
\text { Dir. Daniel de Felippo }\end{array}$ & Argentina & 2012 & Serie TV \\
\hline
\end{tabular}

Tabla 1. Documentales, películas y series de TV sobre apropiación de menores

Para novelas, cuentos y obras de teatro propongo el siguiente cuadro:

\begin{tabular}{|l|l|l|l|}
\hline Título & Autor / Nacionalidad & Año & Género \\
\hline $\begin{array}{l}\text { A veinte años, } \\
\text { Luz }\end{array}$ & Elsa Osorio (Argentina) & 1998 & Novela \\
\hline
\end{tabular}




\begin{tabular}{|c|c|c|c|}
\hline $\begin{array}{l}\text { Conversación al } \\
\text { Sur }\end{array}$ & Marta Traba (Argentina) & 1981 & Novela \\
\hline $\begin{array}{l}\text { Cuentas } \\
\text { pendientes }\end{array}$ & Martín Kohan (Argentino) & 2010 & Novela \\
\hline $\begin{array}{l}\text { Delincuente } \\
\text { argentino / El } \\
\text { policía descalzo } \\
\text { de la Plaza San } \\
\text { Martín. El } \\
\text { segundo caso del } \\
\text { comisario } \\
\text { Lascano. }\end{array}$ & Ernesto Mallo (Argentino) & $\begin{array}{l}2009 y \\
2011\end{array}$ & Novela (P. Negro) \\
\hline $\begin{array}{l}\text { Diario de una } \\
\text { princesa } \\
\text { montonera }-110 \% \\
\text { verdad - }\end{array}$ & $\begin{array}{l}\text { Mariana Eva Perez } \\
\text { (Argentina) }\end{array}$ & 2012 & $\begin{array}{l}\text { Novela } \\
\text { (Autoficción) }\end{array}$ \\
\hline Dos veces junio & Martín Kohan (Argentino) & 2002 & Novela \\
\hline El hilo rojo & Sara Rosemberg (Argentina) & 1998 & Novela \\
\hline $\begin{array}{l}\text { El pájaro de } \\
\text { hueso }\end{array}$ & María Carman (Argentina) & 2013 & Novela \\
\hline $\begin{array}{l}\text { La aguja en el } \\
\text { pajar / Crimen } \\
\text { en el Barrio de } \\
\text { Once. El primer } \\
\text { caso del } \\
\text { comisario } \\
\text { Lascano. }^{17} \\
\end{array}$ & Ernesto Mallo (Argentino) & 2005 y 2011 & Novela (P. Negro) \\
\hline La apropiación & Ignacio Apolo (Argentino) & 2014 & Novela \\
\hline $\begin{array}{l}\text { La capital del } \\
\text { olvido }\end{array}$ & $\begin{array}{l}\text { Horacio Vázquez-Rial } \\
\text { (Argentino-Español) }\end{array}$ & 2004 & Novela (P. Negro) \\
\hline $\begin{array}{l}\text { La casa de los } \\
\text { conejos }\end{array}$ & Laura Alcoba (Argentina) & 2008 & Novela (Autoficción) \\
\hline $\begin{array}{l}\text { La pasión de } \\
\text { María }\end{array}$ & Carlos Chernov (Argentino) & 2005 & Novela \\
\hline $\begin{array}{l}\text { La rebelión de los } \\
\text { niños }\end{array}$ & $\begin{array}{l}\text { Cristina Peri Rossi } \\
\text { (Uruguaya) }\end{array}$ & 1980 & Cuento \\
\hline Las chanchas $^{18}$ & Félix Bruzzone (Argentino) & 2014 & Novela \\
\hline Los topos & Félix Bruzzone (Argentino) & 2008 & Novela (Autoficción) \\
\hline Memoria falsa & Ignacio Apolo (Argentino) & 1995 & Novela \\
\hline$N N_{12}$ & Gracias Morales (Española) & 2008 & Teatro \\
\hline
\end{tabular}




\begin{tabular}{|l|l|l|l|}
\hline Potestad & $\begin{array}{l}\text { Eduardo Pavlovsky } \\
\text { (Argentino) }\end{array}$ & 1985 & Teatro \\
\hline Presagio & Susana Cella (Argentina) & 2006 & Novela \\
\hline $\begin{array}{l}\text { Quinteto de } \\
\text { Buenos Aires }\end{array}$ & $\begin{array}{l}\text { Manuel Vázquez Montalbán } \\
\text { (Español) }\end{array}$ & 1998 & Novela (P. Negro) \\
\hline $\begin{array}{l}\text { Si un día me } \\
\text { olvidaras }\end{array}$ & $\begin{array}{l}\text { Raúl Hernández Garrido } \\
\text { (Español) }\end{array}$ & 2000 & Teatro \\
\hline Taper Ware & Blanca Lema (Argentina) & 2009 & Novela \\
\hline $\begin{array}{l}\text { Teatro x la } \\
\text { Identidad }\end{array}$ & AAVV & $\begin{array}{l}2001 \text { en } \\
\text { adelante }\end{array}$ & Teatro \\
\hline Una mancha más & Alicia Plante (Argentina) & 2011 & Novela (P. Negro) \\
\hline
\end{tabular}

Tabla 2. Novelas, cuentos y dramaturgias sobre apropiación de niños en el contexto argentino $^{19}$

Además de las producciones mencionadas en las tablas, en 2012 la televisión pública trasmitió quince microdocumentales protagonizados por jóvenes restituidos, quienes han ganado en los últimos años el estatus de "personalidades públicas". En los "micros" se cuenta brevemente la desaparición de los padres, la apropiación y el camino que recorrió cada uno para recuperar su identidad. También se ha realizado una gran cantidad de cortos, trabajos artísticos y literarios producidos por hermanos y familiares de los niños desaparecidos. ${ }^{20}$ Promovidos en un inicio desde las asociaciones APM e H.I.J.O.S. (Hijos por la Identidad y la Justicia contra el Olvido y el Silencio), hoy son parte del patrimonio cultural y memorialístico del país.

De igual manera se han emitido spots publicitarios para recordar la búsqueda y anunciar los teléfonos de contacto, desde el 2001 hasta la actualidad se trasmiten en todas las provincias argentinas, y algunos también en el exterior, como es el caso de Italia. ${ }^{21}$ Con todo esto, la ciudad misma, Buenos Aires, donde se centran la mayor parte de las campañas, ha sufrido un cambio en su fisonomía. La publicidad sobre la identidad ocupa muchísimos espacios públicos, cuando no privados: vallas publicitarias, librerías, teatros, museos, actos públicos, plazas, placas, stands con camisetas, incluso llega a las cajas de comida de Aerolíneas Argentinas. ${ }^{22}$ Los objetos diarios emanan identidad. En este sentido, la labor de $A P M$ ha sido satisfactoria y ha permitido una amplia producción testimonial, histórica y académica que se traduce en un gran número de publicaciones, algunas de ellas pueden encontrarse en acceso libre a través de la página de la asociación. Para el sociólogo Gabriel Gatti la palabra "identidad", cuando está asociada a la desaparición forzada de personas, gana un sitio que no tiene en otros lados y genera cosas: 
Genera centros de atención psicológica (Centro de Atención por el Derecho a la Identidad), organismos oficiales (Comisión Nacional de Identidad), leyes $y$ jurisprudencia nacional e internacional (los llamados "artículos argentinos" de la declaración de derechos surgida por el Convenio Internacional por los Derechos del niño y del Adolescente), también produce redes (Red por la Identidad), archivos (Archivo de la Identidad)... (129; énfasis en el original)

Estas entidades surgidas en torno a la identidad tienen en común dos cuestiones; primero, una "de orden teórico" vinculada a la inflexibilidad. No se trata de una identidad acorde a los nuevos tiempos, "cambiante", sino una que para describirla Gatti apela a adjetivos como "pétrea, estable, firme". La segunda cuestión es de orden práctico: la relación con $A P M$. El modelo sobre el que la mayoría de las organizaciones se asienta requiere que "para que algo (o alguien) tenga identidad posea un nombre, un territorio y una historia estables, es decir, exige que el nombre sea propio y único, que el territorio sea claro y cerrado, que la historia remita un origen inequívoco" (Gatti 130; énfasis en el original). El problema frente a la desaparición forzada de personas es que esta "catástrofe" arrasa con el sentido, despoja a los individuos de nombre, de historia y del tejido social que les otorgaba significado. Frente a esto las organizaciones han creado una "estrategia de resistencia" que intenta devolver el sentido a esos cuerpos, restituirles lo propio: nombre, historia y territorio. Para lograrlo se valen de dos materiales esenciales: la genética y la familia.

Uno de los riesgos que Gatti ve en esta estrategia es la de "exceder el sentido original, ir más allá" (131). Se intenta devolver identidad a partir de lo que eran antes de ser desaparecidos, se pretende que aparezcan y que recobren el estatuto que poseían antes de desaparecer. Gatti se pregunta a partir de esto: "El desaparecido, ¿deja realmente de serlo?" (145). Esas interrogaciones también resuenan en la narrativa de Mariana Eva Perez, no sólo en Diario de una princesa montonera - 110\% verdad - (2012), sino también en Instrucciones para un coleccionista de mariposas, una dramaturgia realizada para el ciclo Teatro $x$ la Identidad. ${ }^{23}$ Luego de encontrar a su hermano apropiado, la narradora expresa el sentimiento de desencuentro. La lucha por la restitución se había desarrollado a partir de reponer la identidad de un bebé apropiado:

No sos Rodolfito, simplemente porque Rodolfito no es nadie más que yo, yo cuando solamente sabía ser tu hermana. No es fácil, pero tengo que dejar que Rodolfito se aleje y te haga lugar a vos, el chico alto de las mil cicatrices de un pasado sin mí. Te dije una vez que eras mi vida. A Rodolfito, mi hermanito, el hijo robado de mamá y papá que era mi vida cuando mi vida era tu ausencia, puedo dejarlo clavado acá, 
con un alfiler, como a esta mariposa. Y que se quede acá, al amparo del cristal, en silencio. (10)

La narrativa de Perez, como las producciones de otros hijos de desaparecidos, dan a Gatti las pistas para pensar la identidad. Ellos logran una "experiencia normalizada de la catástrofe" (147), y esto no se consigue a través de una búsqueda del sentido como fue y sigue siendo en la mayoría de los ámbitos de la memoria, sino dando una vuelta más, rodeando la imposibilidad, aceptando que el sentido es imposible y sobre eso hay que re-fundarse, re-hacerse. De este modo, distingue las narrativas del sentido y las de su ausencia. Las primeras son las que construyen los arqueólogos, antropólogos forenses, archiveros, psicólogos, todos ellos militantes del sentido y asociados a esa identidad "pétrea, estable, firme". Sus trabajos buscan reponer algo que antes había quedado devastado (Gatti 89), recuperan los cuerpos, los nombres, restablece la identidad y el lugar social a los desaparecidos. De estas narrativas Gatti desconfía, recela de sus intentos de detener la "catástrofe" (algo imposible) y percibe en ellas la continuidad de los antiguos pactos de sentido de las cosas, lo que inevitablemente trae consecuencias. Las segundas narrativas, entre las que se incluye, son las que se elaboran desde la "normalidad de la ausencia", construidas a partir de lo que no está, de la falta, las que no insisten en recomponer sino en conformarse a partir de ese lugar incómodo, doloroso, pero al fin y al cabo, propio.

Esta idea, por demás valiosa para analizar la "Nueva Narrativa Argentina" (Drucaroff), resulta insuficiente para los casos españoles. En España la generación que "gestiona" la "catástrofe" ha saltado a los hijos y pasado directamente a los nietos. No convivir con los hechos ya conlleva un distanciamiento físico imposible de sortear. No hay ausencia que habitar, no hay tragedia cotidiana de la cual dar cuenta. En su lugar hay un proceso de apropiación de la historia, de reconocimiento del pasado y de investigación de los acontecimientos.

DIVERGENCIAS DE LOS CASOS

En España no hubo un movimiento organizado como el de Madres/Abuelas o familiares que resistiera durante la dictadura y que se mantuviera en democracia. En España hubo una interrupción de las políticas de memoria, un lapso inadmisible de años entre los hechos y las denuncias. Hay otras cuantiosas diferencias, algunas de las cuales recojo en el siguiente cuadro: $:^{24}$ 


\begin{tabular}{|c|c|c|}
\hline & ARGENTINA & ESPAÑA \\
\hline $\begin{array}{l}\text { Guerra que precede a la } \\
\text { Dictadura }\end{array}$ & $\begin{array}{l}\text { La llamada "Guerra } \\
\text { Sucia". }\end{array}$ & Guerra Civil de 3 años. \\
\hline $\begin{array}{l}\text { Duración del Régimen } \\
\text { Dictatorial y distribución del } \\
\text { poder }\end{array}$ & $\begin{array}{l}7 \text { años: } 4 \text { juntas } \\
\text { Militares, } 11 \text { líderes. }\end{array}$ & 36 años: 1 dictador. \\
\hline $\begin{array}{l}\text { Destino de las embarazadas y } \\
\text { lugar de los partos }\end{array}$ & $\begin{array}{l}\text { Centros Clandestinos de } \\
\text { Detención. A veces eran } \\
\text { trasladadas al Hospital } \\
\text { Militar para los partos. }\end{array}$ & Cárceles franquistas. \\
\hline $\begin{array}{l}\text { Destino de la madre luego del } \\
\text { parto }\end{array}$ & $\begin{array}{l}\text { Generalmente eran } \\
\text { arrojadas al río de La } \\
\text { Plata, o fusiladas y } \\
\text { enterradas en fosas } \\
\text { comunes. }\end{array}$ & $\begin{array}{l}\text { Generalmente eran } \\
\text { fusiladas y enterradas } \\
\text { en fosas comunes. } \\
\text { Otras permanecían en } \\
\text { las cárceles. }\end{array}$ \\
\hline Nivel cultural de las madres & $\begin{array}{l}\text { La mayoría eran } \\
\text { estudiantes } \\
\text { universitarias, o de } \\
\text { secundaria. Mayormente } \\
\text { alfabetizadas. }\end{array}$ & $\begin{array}{l}\text { La mayoría eran } \\
\text { obreras o } \\
\text { trabajadoras. } \\
\text { Mayormente } \\
\text { analfabetas. } \\
\end{array}$ \\
\hline $\begin{array}{l}\text { Tipologías de lo sucedido en el } \\
\text { momento de detención, en la } \\
\text { cárcel o con posterioridad al } \\
\text { asesinato de sus padres. } \\
\text { (Datos según el “Informe } \\
\text { Sábato” y según Irredentas. } \\
\text { Ampliados con información } \\
\text { de otros textos) }\end{array}$ & $\begin{array}{l}\text { Detención: } \\
\text {-Niños dejados en casa } \\
\text { de algún vecino para que } \\
\text { este se hiciera cargo, } \\
\text { hasta la llegada de algún } \\
\text { familiar. Hay casos en } \\
\text { que los vecinos se los } \\
\text { han quedado. } \\
\text {-Niños derivados a } \\
\text { Instituto de menores, } \\
\text { que los entregaban a } \\
\text { familiares o los cedían } \\
\text { en adopción bajo otro } \\
\text { nombre. } \\
\text {-Secuestro del menor } \\
\text { para la posterior } \\
\text { adopción por un } \\
\text { represor o por } \\
\text { ciudadanos ligados a la } \\
\text { Dictadura. } \\
\text { - Entrega directa del }\end{array}$ & $\begin{array}{l}\text { Detención: } \\
\text {-Niños entregados a } \\
\text { algún vecino, que } \\
\text { posteriormente los } \\
\text { dejaba con un familiar } \\
\text { o en los Centros del } \\
\text { Auxilio Social. Por lo } \\
\text { general acababan en la } \\
\text { beneficencia por falta } \\
\text { de recursos. } \\
\text { - Niños trasladados al } \\
\text { Auxilio Social, } \\
\text { hospicios y centros } \\
\text { religiosos, a estos } \\
\text { últimos iban } \\
\text { destinadas } \\
\text { especialmente las } \\
\text { niñas. }{ }^{25} \text { En muy pocos } \\
\text { casos hubo } \\
\text { consentimiento } \\
\text { paterno para el }\end{array}$ \\
\hline
\end{tabular}




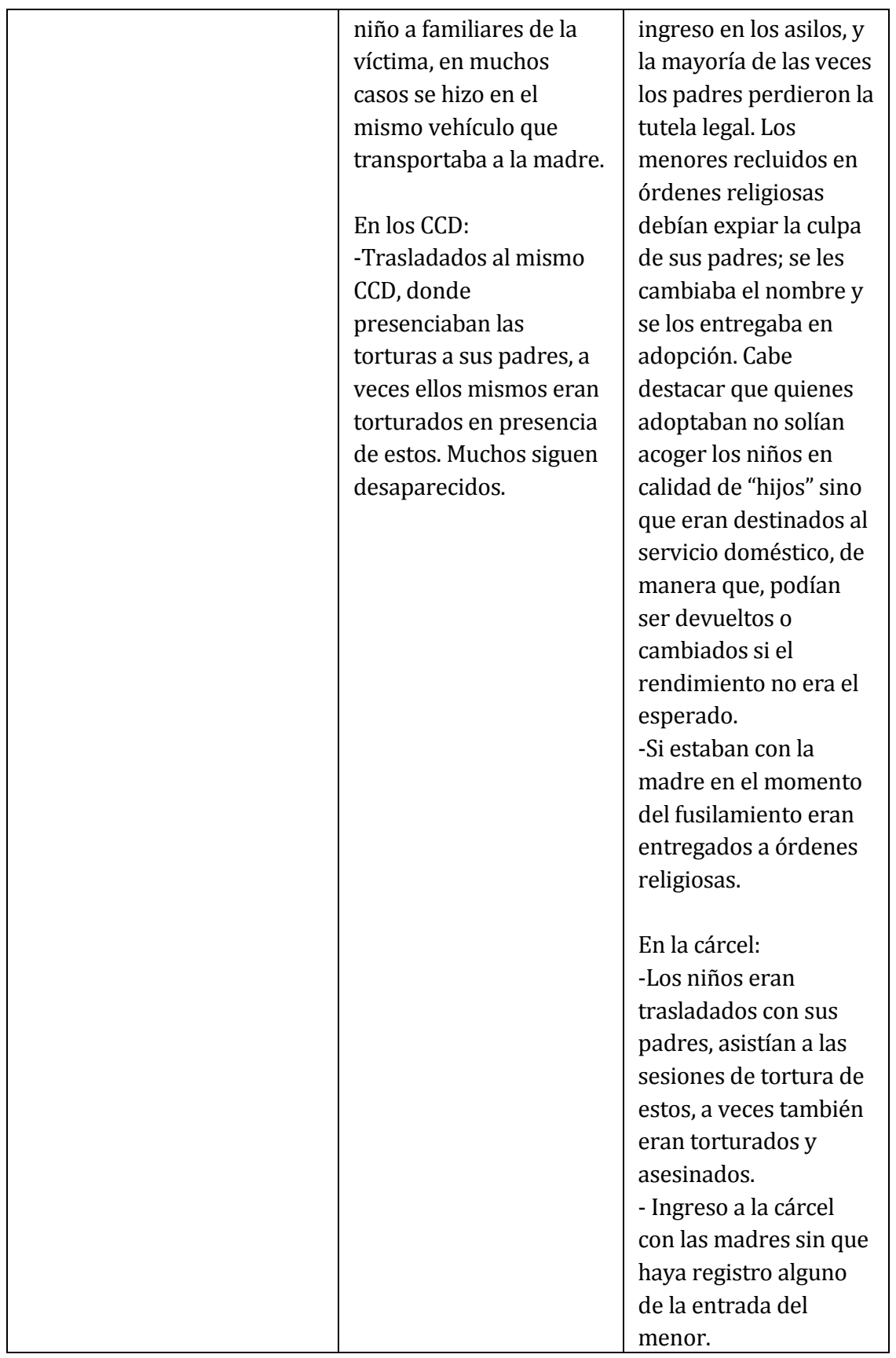




\begin{tabular}{|c|c|c|}
\hline & & $\begin{array}{l}\text {-Los que estaban } \\
\text { dentro de la cárcel } \\
\text { podían morir a causa } \\
\text { de los malos tratos o } \\
\text { por las condiciones del } \\
\text { lugar (hambre, falta de } \\
\text { higiene, epidemias). Si } \\
\text { sobrevivían, a los tres } \\
\text { o cuatro años eran } \\
\text { trasladados a un } \\
\text { destino desconocido } \\
\text { por los padres. } \\
\text { Los exiliados: } \\
\text {-Capturados por la } \\
\text { Falange Española en el } \\
\text { exilio y trasladados a } \\
\text { España sin } \\
\text { consentimiento } \\
\text { paterno. Acababan en } \\
\text { la beneficencia. }\end{array}$ \\
\hline $\begin{array}{l}\text { Índice de "legalidad" de los } \\
\text { robos }\end{array}$ & $\begin{array}{l}\text { El accionar fue } \\
\text { clandestino. No se llegó } \\
\text { a legislar. }\end{array}$ & $\begin{array}{l}\text { El accionar fue público, } \\
\text { enmascarado por } \\
\text { diferentes organismos. } \\
\text { Se creó un marco legal } \\
\text { para los robos. }\end{array}$ \\
\hline $\begin{array}{l}\text { Finalidad de la } \\
\text { Apropiación/Expropiación }\end{array}$ & $\begin{array}{l}\text { Reeducación según la } \\
\text { ideología dictatorial. } \\
\text { Aniquilación del gen } \\
\text { "subversivo". }\end{array}$ & $\begin{array}{l}\text { Reeducación según la } \\
\text { ideología dictatorial. } \\
\text { Aniquilación del gen } \\
\text { "rojo". }\end{array}$ \\
\hline $\begin{array}{l}\text { Número aproximado de niños } \\
\text { apropiados / expropiados }^{26}\end{array}$ & $\begin{array}{l}\text { Aproximadamente } 500 \\
\text { en todo el periodo. }\end{array}$ & $\begin{array}{l}\text { Alrededor de } 42.000 \\
\text { (solo con cifras hasta } \\
\text { mediados de los } \\
\text { cincuenta) }\end{array}$ \\
\hline $\begin{array}{l}\text { Número de niños que han } \\
\text { recuperado la identidad }\end{array}$ & $\begin{array}{l}117 \text { hasta septiembre de } \\
2015 .\end{array}$ & No hay datos. \\
\hline $\begin{array}{l}\text { Tiempo de reacción de las } \\
\text { Investigaciones con respecto a } \\
\text { la finalización de las } \\
\text { Dictaduras }\end{array}$ & $\begin{array}{l}\text { Las investigaciones } \\
\text { comienzan antes de } \\
\text { acabar la dictadura, } \\
\text { llevadas adelantes por } \\
\text { organismos de Derechos }\end{array}$ & $\begin{array}{l}\text { Las investigaciones } \\
\text { comienzan en el } 2002 . \\
27 \text { años después de la } \\
\text { muerte de Franco. } \\
\text { Avanzan muy }\end{array}$ \\
\hline
\end{tabular}




\begin{tabular}{|c|c|c|}
\hline & $\begin{array}{l}\text { Humanos. } \\
\text { Principalmente } A P M \text {. }\end{array}$ & $\begin{array}{l}\text { lentamente y por } \\
\text { iniciativas privadas. }\end{array}$ \\
\hline $\begin{array}{l}\text { Recursos para la } \\
\text { identificación }\end{array}$ & $\begin{array}{l}\text {-CONADI } \\
\text {-Banco Nacional de } \\
\text { Datos genéticos. } \\
\text {-Equipo forense. } \\
\text {-Equipo Psicológico. } \\
\text {-Otros. }\end{array}$ & $\begin{array}{l}\text {-Los estudios } \\
\text { genéticos aún se hacen } \\
\text { en laboratorios } \\
\text { privados, a coste de los } \\
\text { interesados. }\end{array}$ \\
\hline $\begin{array}{l}\text { Leyes de carácter nacional } \\
\text { para la recuperación de los } \\
\text { niños }\end{array}$ & $\begin{array}{l}\text { Ley Nacional № } 23 \cdot 51^{27} \\
\text { Ley Nacional № } 25 \cdot 457^{28} \\
\text { Ley Nacional № } 25 \cdot 914^{29} \\
\text { Decreto № } 715 / 2004^{30}\end{array}$ & Auto juez Garzón. \\
\hline
\end{tabular}

Tabla 3. Análisis comparativo

Por la divergencia en los datos, mucho más significativas en los números que en el móvil, por las variantes de duración de la dictadura y la magnitud de los genocidios, los casos pueden permitirse una revisión conjunta pero no una homologación. No es lo mismo una y otra víctima. De hecho, las víctimas españolas aun están conformándose como tales, nucleándose, organizándose. Puede mirarse a Argentina para pensar procedimientos y métodos de búsqueda, muchos de los cuales ya han sido enunciados por Miguel Rodríguez Arias, pero quizás habría que preguntarse en qué medida esto serviría, ¿los mecanismos que ayudaron a encontrar niños en Argentina pueden ser útiles en el Estado español actual? Y si lo son en algún punto, tendrán que ser adaptados a otras necesidades de memoria e identidad. Aun así, es improbable llegar a resultados favorables con los casos de los menores expropiados durante las primeras décadas de la dictadura, muchos de ellos ya ancianos y sin familiares con quienes cotejar su ADN. Sí podrían albergarse más esperanzas en lo que compete a los casos de los niños robados en la última etapa del franquismo y en democracia.

De igual manera que con los casos concretos de apropiación/expropiación, no se puede homologar la producción cultural en los dos países, ni en forma, ni en número, ni en la necesidad que pretenden solventar. Si se tiene en cuenta que el relato sobre el pasado puede ser modificado por los cambios sociales del presente; la literatura de expropiación, es decir, este incipiente corpus presentado, susceptible de ser ampliado en los próximos años, está configurando su lugar en el canon, intenta dejar una huella en una memoria colectiva hispánica. Transformar el recuerdo individual y del conjunto de la comunidad para que, en un futuro, la idea de franquismo esté ligada también a la expropiación de 
menores, de igual manera que para el caso argentino la apropiación es un término insustituible de la tragedia. Es necesario alentar el proceso de fijación de estos términos para lograr un afianzamiento positivo y ecuánime con el pasado, es imperioso también para reconocernos como sociedad.

Para concluir, retomo el epígrafe de este artículo que rememora las palabras de Liliana Heker en El fin de la historia con el propósito de hablar de la catástrofe, ese lugar desde el que no se puede volver y que solo es aprehensible desde una narrativa que desdibuje los límites entre la ficción y los documentos. Toda la producción hispánica que he mencionado y que gira en torno a las expropiaciones, la infancia en guerra, la orfandad, la violencia, tiene la voluntad de mirar hacia el pasado porque con ello se construye como artefacto de memoria colectiva, como parte del nuevo modelo de revisión histórica que se está gestando. Es así como la producción cultural alrededor de los niños apropiados/expropiados por las dictaduras ha intervenido en los campos de batalla de las políticas española y argentina con la intención de forjar una memoria pública del horror.

Universidad de Valencia

\section{NOTAS}

1 La preocupación por la filiación se hizo presente desde los dramas genealógicos de Lope de Vega. Para un estudio sobre la dramatización de la materia genealógica en Lope de Vega ver Ferrer. Asimismo, Joan Oleza estudia la bastardía en el teatro del siglo XVII, donde se ocupa de obras como El bastardo Mudarra, El casamiento en la muerte, El pleito por la honra o el valor de Fernandico. También pueden incorporarse a este estudio obras cumbres como La vida es sueño de Pedro Calderón de la Barca, con un Segismundo preguntando a una Rosaura de identidad cambiada ¿Quién eres? (v. 194), definiéndose a sí mismo, aún encerrado y huérfano, como "un esqueleto vivo", "un animado muerto" (vv. 201-202).

2 Actualmente se está discutiendo si el concepto "apropiación" sigue siendo o no funcional para describir todo el proceso y todos los afectados del robo de niños por parte del Estado dictatorial. Mariana Eva Perez, hija de desaparecidos y autora de Diario de una princesa montonera - $110 \%$ Verdad -, juzga insuficiente el concepto "apropiar", ya que su estandarización se centra en "el apropiado" y "los apropiadores" pero deja fuera muchas otras víctimas, como son los familiares. Por otro lado, sostiene que este término no alcanza 
porque "excluye a todos aquellos que se analizaron en el Bco. de Datos Genéticos y no coincidieron con ninguna familia. Ellos también son otra cara de esto que se llama mal "apropiación" y están más invisibilizados que nadie" (Perez, "Versión").

3 Realizo un análisis más detallado sobre los conceptos expropiación/apropiación y el contexto histórico español en mi artículo "Panorama sobre la expropiación de niños en la dictadura franquista.

Propuesta terminológica, estado de la cuestión y representaciones en la ficción".

$4 \quad$ Para un análisis sobre las consecuencias de la Transición española en la política actual española ver Mate.

5 Tal es el caso del Equipo Argentino de Antropología Forense que colabora con la ARMH en las exhumaciones (Vidal).

6 El 8 de octubre del 2000 Emilio Silva, nieto del primer exhumado con métodos forenses en España, habla por primera vez de "desaparecidos" para referirse a los republicanos represaliados y enterrados en fosas comunes, instaurando, de este modo, una asociación con los desaparecidos de las dictaduras del Cono Sur. Pasarían dos años más antes que las crónicas de las exhumaciones aparecieran en los periódicos. Entre el 2000 y el 2002 solo se publicaron notas sueltas. Entre ellas quiero destacar la de Vázquez Montalbán en Interviú (11/12/200o), ya que recuperando la expresión de Silva potencia la mirada transatlántica sobre las exhumaciones, titula su artículo "Los desaparecidos".

7 Hace un tiempo me acerqué a uno de los encuentros mensuales que hacen conjuntamente las asociaciones de robos de niños en Valencia. Afectados de todo el país se reúnen en la Plaza de la Virgen para reclamar la apertura de las causas que se han cerrado sin resolverse. La similitud con las primeras manifestaciones argentinas es impactante. Los afectados llevan carteles colgados en el pecho con las fotos de sus familiares y dan vueltas a la Plaza de la Virgen en sentido contrario a las agujas del reloj. Pero entre aquellos primeros encuentros de las Madres de Plaza de Mayo y estos, los que se están produciendo en España, han pasado casi cuarenta años. Aquellos comenzaron en dictadura y estos en una avanzada democracia. ¿Qué motiva a estos manifestantes, la mayoría hermanos de niños robados, a imitar - consciente o inconscientemente - una lucha que se produjo en otras condiciones y a 12.000 km de distancia?

8 Se emitió en el marco de la serie La nostra memoria. Poco tiempo después de Els nens perduts del franquisme se televisó Les fosses del silenci (2003), con un impacto similar.

9 Estas indagaciones continuaron en estudios posteriores del historiador. En 2004 Vinyes publicó El daño y la memoria, donde recogió las experiencias de María Salvo Iborra, desde la construcción de su conciencia política durante la 
Segunda República y la Guerra Civil, pasando por el exilio y los campos de concentración franceses, hasta los 16 años en las cárceles franquistas (Les Corts, Las Ventas, Segovia, Alcalá de Henares).

1o La primera entrega de Paracuellos vio la luz en la revista Muchas gracias, pero antes debió pasar la censura, ya que muchas de las historietas fueron modificadas para su publicación. En la edición que realizó Ediciones de la Torre en 1979 se publicó por primera vez la versión sin recortes. La serie tiene dos etapas: la primera (finales de los 70 - comienzo de los 8o) tiene 28 episodios y un total de 90 páginas que se recogen en dos álbumes, Paracuellos y Paracuellos 2. La segunda etapa comienza en 1997 y finaliza en 2003, consta de 26 episodios que suman 192 páginas distribuidas en 4 álbumes, Paracuellos 3, 4, 5 y 6 respectivamente. Para un análisis de Paracuellos como "cómic responsable" ver mi artículo "Carlos Giménez y la construcción de la memoria colectiva: el caso de Paracuellos". Para un acercamiento a la historieta como instrumento de abordaje del pasado traumático en España y Argentina ver Bórquez ("Historias").

"1 Miguel Janicot del Castillo nació en Madrid el 3 de agosto de 1933. Su padre fue Michel Janicot, un rico terrateniente francés. Su madre, una noble española comprometida con la república, Cándida Isabel del Castillo. Para una aproximación a Cándida del Castillo y a su labor de la República ver Formica.

12 María Topete Fernández fue la directora de la Prisión de Madres Lactantes, inaugurada el 17 de septiembre de 1940. Anteriormente había estado en Las Ventas como funcionaria jefa de servicios, donde ya se había ganado la fama de crueldad. Provenía de la pequeña aristocracia y se relacionaba con los círculos de poder, dedicaba todo su tiempo a la prisión y al propósito de reeducación de los menores de las "rojas". Durante la guerra había sido detenida por el ejército republicano y encarcelada por milicianas, episodio que endureció su trato y desprecio por las mujeres que intentaban subvertir el orden de clases y de género establecido. Es retomada como personaje en Si a los tres años no he vuelto y en La sonrisa del caudillo.

13 En 1974 Pérez Esquivel funda el Servicio de Paz y Justicia, en 1975 se crea La Asamblea Permanente por los Derechos Humanos, constituida por diversos partidos políticos. En 1976 nace el Movimiento Ecuménico por los Derechos Humanos, única agrupación formada por religiosos argentinos. Para más información ver Silva.

14 Las Asociaciones Madres y Abuelas nacen bajo la misma necesidad de saber qué sucedió con sus hijos y conseguir justicia, se diferencian en que Abuelas extiende su búsqueda a los nietos desaparecidos y a lograr las restituciones. Se trata de dos entidades diferentes, actualmente Abuelas de Plaza de Mayo está presidida por Estela de Carlotto, Madres de Plaza de Mayo por Hebe Bonafini. En 1986, a causa de divergencias en cuanto al Juicio a las Juntas y a las medidas 
del gobierno de Raúl Alfonsín, la asociación de Madres se dividió, a su vez, en Madres de Plaza de Mayo y Madres de Plaza de Mayo línea fundadora. Para un análisis exhaustivo de la historia de Madres ver Gorini.

15 La Corte Suprema bonaerense desclasificó, en 2006, 4.295 habeas corpus de los primeros años del Proceso, uno de ellos fechado el 15 de mayo de 1977 es de 13 abuelas que buscaban a sus nietos: "Somos un grupo de mujeres mayores que poco a poco nos hemos ido encontrando en los Tribunales, en la Casa Cuna, Iglesias, regimientos, comisaría, en una incesante y desesperada búsqueda de nuestros nietitos". Este documento se constituye como el primero que perfila a la Asociación (Dandan)

16 Bajo la presidencia de Néstor Kirchner el Congreso dictó la nulidad de las Leyes de Obediencia Debida y Punto Final (2003). En el año 2005 la Corte Suprema de Justicia declaró la inconstitucionalidad de dichas leyes y se reabrieron las causas judiciales. Reforzando el simbolismo del giro que estaba dando el país, el 24 de marzo de 2004, en el primer aniversario del golpe militar en el que Néstor Kirchner era presidente, mediante un acto público ordenó que descolgaran del Colegio Militar los cuadros de los represores Jorge Rafael Videla y Reynaldo Benito Bignone. También se estableció que dos ex Centros Clandestinos, la ESMA en Buenos Aires y La Perla en Córdoba, fueran utilizados como lugares de memoria y promoción de los derechos humanos. Asimismo se instituyó como feriado nacional el 24 de marzo. Con estos actos no solo se reabrieron todos los casos y se comenzaron a imputar a los responsables, también hubo una transformación cultural y social.

17 Tanto Crimen en el barrio de Once... como El policía descalzo... son nuevas ediciones de las novelas La aguja en el pajar (2005) y Delincuente argentino (2009), del mismo autor. Por esta razón se han mencionado dos títulos y dos fechas de edición.

Aunque en la novela no se trata explícitamente la apropiación de niños por parte del Estado, sí se hace mención al robo de una hermana gemela y a una búsqueda que define el sentido de la vida: "Y era como si la idea de tener una hermana perdida por ahí me ayudara a vivir" (Bruzzone 111). Por otro lado, incluyo Las chanchas porque, leído en consonancia con el resto de la obra del autor, continúa la indagación sobre la identidad a partir de la falta.

19 Dado que el fin de este artículo es hacer un panorama general de los productos culturales en torno a la expropiación/apropiación de menores, no me detendré en análisis de las narraciones. Para Dos veces junio, Cuentas pendientes, ver Souto, "Los subalternos". Para Diario de una princesa montonera y Los topos ver Cobas, "Narrar".

$20 \quad$ En la página de Abuelas de Plaza de Mayo se pueden ver $A$ zo años no nos han vencido (2006), realizado por nietos restituidos y nietos que buscan a sus hermanos, y Cada vez somos más (2011), realizado por el nieto Sabino Abdala. 
21 El 22 de octubre de 2012 se publicó en Página/12 el lanzamiento de una campaña en Turín. El mismo día que Roma recordaba la desaparición de 350 niños judíos deportados a campos de concentración entre octubre de 1943 y junio de 1944, Argentina presentó la campaña "Por la identidad" destinada a la búsqueda en el exterior de los 393 nietos/as que aún faltaban. La misma ya se había presentado en Nápoles, Bari y Consenza, República de San Marino y Milán. La "Red Nacional por el derecho a la identidad" que se extiende ya por varios países fue creada en 2003 con el fin de llegar a las provincias argentinas más alejadas de la Capital. Ahora ha excedido las fronteras y también está gestionando la colaboración con diferentes ayuntamientos europeos. Por otro lado, están agilizando el trámite para que las pruebas de ADN se puedan hacer en los consulados, ya no será necesario viajar a Argentina si existen dudas sobre la procedencia.

22 La búsqueda de $A P M$ invade también el espacio aéreo. Entre las publicidades de los lugares turísticos recomendables para visitar en Argentina, los alfajores y galletas típicas que ofrece la aerolínea, se puede ver el logo de la asociación con el lema "Identidad. Familia. Libertad" y el llamado a quienes no se han realizado aún las pruebas de ADN.

23 Mariana Eva Perez escribe su apellido sin acento. Es una decisión que atañe a la identidad.

24 La información del cuadro está basada en diversos textos mencionados en la bibliografía. Principalmente Vinyes, Irredentas (2002).

25 El cómic Cuerda de Presas destaca la distinción de géneros en el momento de los traslados de los menores: "Las niñas a una institución religiosa, los niños al hospicio o al Auxilio Social" (García y Martínez 44).

26 Las cifras argentinas se basan en las de APM y el Informe Nunca Más, las españolas en los datos recogidos por Vinyes. El Patronato de San Pablo contabilizó zo.ooo hijos encarcelados y exiliados entre 1944 y 1954, a este número hay que agregarle $\mathbf{1 2 . 0 0 0}$ del Patronato de la Merced, la institución que le precedió. La magnitud de las cifras también se resalta en la ficción; en Mala gente que camina Urbano las utiliza para argumentar ante Lisvano sobre la fiabilidad de los datos: "lo único que tienes que hacer para comprobarlo es mirar las cifras oficiales que dio el patronato de San Pablo, que en 1944 alardeaba de haber acogido bajo la tutela del Estado a treinta y un mil niños" (Prado 426).

27 Ley de 1987 por la que se crea el Banco Nacional de Datos Genéticos.

28 Ley de 2001, regula la CONADI (Comisión Nacional Argentina por el Derecho a la Identidad).

29 La Ley 25.914 establece beneficios para las personas que hubieren nacido durante la privación de la libertad de sus madres, o que siendo menores hubiesen permanecido detenidos en relación a sus padres, siempre que 
cualquiera de éstos hubiese estado detenido y/o desaparecido por razones políticas, ya sea a disposición del Poder Ejecutivo Nacional y/o tribunales militares; y para aquellas que por alguna de esas circunstancias, hayan sido víctimas de sustitución de identidad (Argentina).

30 Por el mismo se crea la Unidad Especial de Investigación de la Desaparición de niños en el seno de la CONADI.

\section{OBRAS CITADAS}

"Área Psicológica. Derecho a la identidad". Abuelas de Plaza de Mayo. S. pag. Web. Argentina. Senado y Cámara de diputados. Derechos humanos Ley 25.914. 25 agosto 2004. S. pag. Web.

ARMENGOU, MONTSE, RICARD BELLIS Y RICARD VINYES. Els nens perduts del

franquisme. Barcelona: Proa, 2002.

BARTHES, ROLAN D. Ensayos críticos. Barcelona: Seix Barral, I973.

B ÓRQUEZ, NÉSTOR. "Historias y viñetas, una versión del pasado traumático". Olivar. Revista de Literatura y Cultura Españolas 20 (2013): III-I69.

BRUZzone, FÉLix. Las chanchas. Buenos Aires: Mondadori, 2014.

-. Los topos. Buenos Aires: Mondadori, 2008.

BUREN, RUBÉN. "La sonrisa del caudillo”. Kamchatka. Revista de análisis cultural 3

(2OI4): Anexo II-84.

CALDERón De la barCa, PedRo. La vida es sueño. Ed. Evangelina Rodríguez

Cuadros. Madrid: Espasa Calpe, 1997.

Calveiro, Pilar. "Los usos políticos de la memoria”. Sujetos sociales y nuevas

formas de protesta en la historia reciente de América Latina. Ed. Gerardo

Caetano. Buenos Aires: Clacso, 2006. 359-382.

CAÑ IL, ANA. Si a los tres años no he vuelto. Madrid: Espasa Libros, $201 \mathrm{I}$.

CAS Tillo, Michel DEL. Tanguy. Historia de un niño de hoy. Trad. Olga Beltrán de

Nanclares. Vitoria: Ikusager-Correria, I999.

CоBAS, ANDREA. "Narrar la ausencia. Una lectura de Los topos de Félix Bruzzone y de Diario de una princesa montonera de Mariana Perez". Olivar. Revista de Literatura y Cultura Españolas 20 (2013): 23-45.

Con A I. Informe de la Comisión Nacional sobre la Desaparición de Personas. Nunca Más. Buenos Aires: Eudeba, 1999.

DANDAn, alejAndRA. "El otro archivo de la memoria”. Página 129 de abril de 2006.

DRUCAROFF, ELSA. Los prisioneros de la torre. Política, relatos y jóvenes en la postdictadura. Buenos Aires: Emecé, $201 \mathrm{I}$.

Els internats de la por. Dir. Montse Armengou y Ricard Belis. Televisió de Catalunya, 2015.

ESTESO POVES, MARíA. Niños robados. De la represión franquista al negocio. Madrid:

Diagonal, 2012. 
Fernández, Verónica e ignacio del moral. Presas. Madrid: Ministerio de

Cultura, 2007.

FERRER VALLS, TERESA. "Lope de Vega y la dramatización de la materia

genealógica (1)". Teatro Cortesano en la España de los Austrias. Cuadernos de

Teatro Clásico 10 (1998): 215-231.

FOR MICA, MERCEDEs. Espejo roto, y espejuelos. Madrid: Huerga y Fierro, 1998.

garcía, jorge y fidel martínez. Cuerda de presas. Bilbao: Astiberri, 2005.

GATTI, GA B R IEL. Identidades desaparecidas. Peleas por el sentido en los mundos de

la desaparición forzada. Buenos Aires: Prometeo, 2011.

giméne Z, CARlos. Todo Paracuellos. 7ª edición. Barcelona: Debolsillo, 2012.

GORIN I, U LISES. La rebelión de las madres. Buenos Aires: Norma, 2006.

Heker, Liliana. El fin de la historia. Buenos Aires: Alfaguara, 1996.

hernández garrido, raúl. Si un día me olvidaras. Madrid: Caos Editorial, 2001. коH AN, M AR Tín. Cuentas pendientes. Barcelona: Anagrama, 2010.

—. Dos veces junio. Buenos Aires: Sudamericana, 2002.

Les fosses del silenci. Dir. Montse Armengou y Ricard Belis. Televisiò de Catalunya, 2003.

MACCIUCI, RAQUEL y POCHAT, MARía, comp. Entre la memoria propia y la ajena.

Tendencias y debates en la narrativa española actual. La Plata: Ediciones del

lado de acá, 2010.

MATE, REYEs. "Memoria y construcción política". La memoria novelada. Vol. 3. Eds. Juan Carlos Cruz Suárez, Hans Lauge Hansen y Antolín Sánchez Cuervos. Bern:

Peter Lang, 2015. 25-38.

MORALES, GRACIA "NN12". Muestra teatro.com 2008. Web.

muñoz molina, antonio. Sefarad. Madrid: Punto de lectura, 2002.

OLEZA, J OAN: "Variaciones del drama historial en Lope de Vega”. Anuario Lope de

Vega. Texto, literatura, cultura 29 (2013): 151-187.

PEREZ, MAR IANA. Diario de una princesa montonera-110\% Verdad-. Buenos Aires:

Capital Intelectual, 2012.

—.."Instrucciones para un coleccionista de mariposas". Kamchatka. Revista de análisis cultural 3. (2014): Anexo 3-10.

—. "Versión novelada". Diario de una princesa montonera - 110\% Verdad. Blogspot 20 agosto 2013. S.pag. Web.

PRAD o, Benjamín. Mala gente que camina. Madrid: Santillana, 2007.

Ri P L L, La l LA. Trilogía de la memoria. Atra Bilis. Los niños perdidos. Santa

Perpetua. Bilbao: Artezblai, 2013.

ROD Ríg U Z Z A R A S, M I G U L L. El caso de los niños perdidos del franquismo: crimen contra la humanidad. Valencia: Tirant lo Blanch, 2008.

SILVA, LU D M L A DA. No habrá flores en la tumba del pasado. La experiencia de la reconstrucción del mundo de los familiares de desaparecidos. La Plata: Al

Margen, 2001. 
So u t o, Luz c. "Carlos Giménez y la construcción de la memoria colectiva: el caso de Paracuellos". Actas del Tercer Congreso Internacional Viñetas Serias, octubre 8-II, 20I4: Mesa en historieta y política. Coord. Amadeo Gandolfo. Buenos Aires: Viñetas Serias, 2015. 39-5I. Web.

—."Panorama sobre la expropiación de niños en la dictadura franquista. Propuesta terminológica, estado de la cuestión y representaciones en la ficción".

Kamchatka. Revista de análisis cultural 3 (2014): $7 \mathrm{I}^{-} 96$.

—."Los subalternos en las ficciones sobre apropiación de menores”. Mitologías Hoy. Revista de pensamiento, crítica y estudios literarios latinoamericanos 8 (2013): $4^{-}-57$.

Torneu-me el fill!. Dir. Montse Armengou y Ricard Belis. Televisió de Catalunya, $2 \mathrm{OI} 2$.

VÁZqUE Z montalBán, MANUEl. "Los desaparecidos”. Interviú II diciembre 2000. S. pag. Web.

VIDAL, LUIS. "La ARMH estrecha la relación con Argentina para identificar a represaliados". La Vanguardia 2 noviembre 2015. S. pag. Web.

VIN Y ES, R ICARD. Irredentas. Las presas políticas y sus hijos en las cárceles de Franco. Madrid: Temas de Hoy, 2002.

—. El daño y la memoria. Las prisiones de María Salvo. Barcelona: Plaza y Janés, 2004 .

WILDE, OSCAR. "La importancia de llamarse Ernesto". Obras Completas. Vol I. Madrid: Aguilar, 2003. 449-509. 